\title{
Proton MR spectroscopy in characterization of focal bone lesions of peripheral skeleton
}

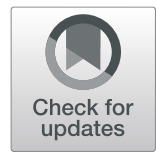

\author{
Meenu Amar ${ }^{1}$, Rohini Gupta Ghasi ${ }^{*}$ (D) L. G. Krishna ${ }^{2}$ and Geetika Khanna ${ }^{3}$
}

\begin{abstract}
Background: The aim of our study was to determine the value of single-voxel proton MR spectroscopy ('HMRS) in distinguishing benign from malignant focal bone lesions in the peripheral skeleton. MRI and ${ }^{1} \mathrm{HMRS}$ was performed in 50 focal lesions (> $1 \mathrm{~cm}$ size) detected on radiographs of peripheral skeleton. ${ }^{1} \mathrm{HMRS}$ was performed at $1.5 \mathrm{~T}$ with TE of 144 ms with automatic shimming and water suppression. Qualitative analysis for a discrete choline peak at 3.2 ppm was done. Significance of the presence of choline peak on ${ }^{1} \mathrm{HMRS}$ in distinguishing benign from malignant lesions was calculated using histopathology as a gold standard. Chi-square test was used and $p$ value $<0.05$ was considered significant.

Results: Forty-one benign and 9 malignant lesions were confirmed by histopathological results. Amongst malignant lesions, choline peak was positive in all but 1 case of low-grade lymphoma. MR spectra of 11 benign lesions showed the presence of choline peak. All 7 benign giant cell tumors (GCT) were positive for choline peak. The sensitivity, specificity, PPV, NPV of proton MR spectroscopy in differentiating benign from malignant lesions were $87.5 \%, 71 \%$, $38.8 \%$, and $96.4 \%$ respectively. $p$ value was significant $(<0.05)$.

Conclusion: ${ }^{1} \mathrm{HMRS}$ in focal bone lesions can help in the differentiation of malignant from benign musculoskeletal tumors. Although some benign lesions may show false-positive result, absence of choline peak is a reliable reassurance against malignancy. GCT is an exception amongst benign bone tumors as it consistently shows the presence of choline peak on ${ }^{1}$ HMRS.
\end{abstract}

Keywords: Proton MR spectroscopy, Choline peak, Bone tumors, Musculoskeletal, Giant cell tumor

\section{Background}

Conventional MR morphological indicators are not always adequate for distinguishing benign from malignant lesions or determining histological composition. The true extent of viable tumor versus necrosis, prognosis, and response to treatment are important questions that often remain unanswered. Such patients benefit from advanced MR imaging techniques like dynamic contrastenhanced MRI, ${ }^{1} \mathrm{H}$ MR spectroscopy, diffusion-weighted MRI, and chemical shift imaging [1].

MR spectroscopy was introduced as early as 1973 as a non-invasive modality that could detect signals of metabolites within a specified region of interest [2]. An elevated level of choline compounds, which are markers of cell membrane turnover, can be used to detect

\footnotetext{
* Correspondence: rohini1912@gmail.com

1 Department of Radiodiagnosis, VMMC \& Safdarjung hospital, New Delhi

110029, India

Full list of author information is available at the end of the article
}

malignancy. ${ }^{1} \mathrm{HMRS}$ is routinely used in the brain and its role is increasing in other areas like prostate and breast cancer [3]. There are various challenges unique to bone MR spectroscopy including heterogeneity, excess of lipids and creatine masking the other metabolites, difficult shimming, etc. [4]. Very few studies have been done to study ${ }^{1}$ HMRS in bone lesions. The earliest study in musculoskeletal MRS was published as late as 2004 where ${ }^{1}$ HMRS was performed in both bone and soft tissue tumors and a relationship between the presence of choline in malignant tumors was emphasized [5]. Further, MR spectroscopy of soft tissue tumors has lesser magnetic susceptibility constraints than osseous tumors and most studies have included both bone and soft tissue masses. The sample sizes of available studies are small. There is no consensus on the technique of spectroscopy or quantification methods or even the interpretation of results. ${ }^{1}$ HMRS has presently no welldefined role in the workup of bone lesions. 
The present study is focused to determine the role of ${ }^{1} \mathrm{H}$ MR spectroscopy in focal bone lesions and the value of choline in differentiating benign and malignant bone lesions.

\section{Methods \\ Patients}

The study was performed after institutional review board approval.

\section{Inclusion criteria}

Fifty patients detected with focal lytic or sclerotic lesions of the peripheral skeleton seen on 2 orthogonal radiographic planes were included in the study.

\section{Exclusion criteria}

Lesions smaller than $1 \mathrm{~cm}$ size or those not amenable to biopsy and patients with contraindications to MRI were not included.

\section{Technique}

MRI was done with a $1.5 \mathrm{~T}$ (Philips Achieva) scanner. Coil selection was done as per the location of the lesion. Surface coils were preferred. Conventional MR imaging was done in all cases using routine institutional protocols. Intravenous contrast was administered if required for the morphological evaluation. In patients with multiple lesions, the lesion planned for biopsy was assessed on MRI.

Single-voxel spectroscopy data was acquired using a point-resolved spectroscopy sequence (PRESS) at intermediate TE $(144 \mathrm{~ms})$. The largest possible voxel size was used. Water suppression was used in every case. Automatic shimming was performed to obtain spectra of acceptable line width. Data was acquired at a spectral bandwidth of $1000 \mathrm{~Hz}$ and 128-256 signals were averaged. In lesions with considerable heterogeneity, multiple voxels were placed. Voxel placement was done carefully to avoid cystic and necrotic areas and include the most enhancing areas.

\section{MRS interpretation}

Spectra were evaluated for technical adequacy. Failure of the spectroscopy examination was defined as a spectrum containing only noise without any identifiable metabolite peaks, insufficient water suppression, excessive lipid contamination, or insufficient field homogeneity.

The spectra were qualitatively analyzed for the presence or absence of a discrete choline peak at $3.2 \mathrm{ppm}$ by visual detection. In cases where a choline peak was not clearly discernible, choline/SNR ratio $>2$ was taken as a positive choline peak.

\section{Statistical analysis}

MRS findings were retrospectively correlated with histopathological diagnosis. Lesions showing inadequate spectrum were excluded from the study. Sensitivity, specificity, positive predictive value, negative predictive value of ${ }^{1}$ HMRS in differentiating benign from malignant lesions was calculated using histopathology as a reference standard. Chi-square test was performed for statistical analysis. $p$ value of $<0.05$ was considered significant.

\section{Results}

Forty-one of the 50 lesions were diagnosed to be benign on histopathology while 9 were proven to be malignant. The number of patients with each final diagnosis is tabulated in Table 1.

46/50 spectra were adequate for interpretation. The 4 technically inadequate spectra were obtained in GCT $(n=1)$, osteomyelitis $(n=2)$, and low-grade malignant parosteal osteosarcoma $(n=1)$. The spectra in GCT and osteomyelitis showed no discrete identifiable peaks, while the spectrum in parosteal osteosarcoma showed a lot of noise overlapping the signal of metabolite peaks. These cases were excluded from analysis on the basis of technical inadequacy.

Out of 46 lesions with adequate spectra, 38 were benign and 8 were malignant on histopathology.

Amongst these, a discrete choline peak was present in 7 malignant and 11 benign lesions. Choline peak was not detected in one case of low-grade lymphoma. Eleven benign lesions showing choline peak were GCT $(n=7)$,

Table 1 Final histopathological diagnosis and number of patients

\begin{tabular}{ll}
\hline Final histopathological diagnosis & No. of patients \\
\hline Benign lesions & 11 \\
Pyogenic osteomyelitis & 7 \\
Tubercular osteomyelitis & 8 \\
Giant cell tumor & 5 \\
Osteochondroma & 4 \\
ABC & 3 \\
FD & 1 \\
Chondromyxoid fibroma & 1 \\
Juxtacortical chondroma & 1 \\
NOF & \\
Malignant lesions & 5 \\
Osteosarcoma & 2 \\
Metastasis & 1 \\
Lymphoma & 1 \\
Chondrosarcoma & \\
\hline
\end{tabular}


chondromyxoid fibroma $(n=1)$, and osteomyelitis $(n=3)$ including 1 case of tuberculosis.

Seven malignant tumors which showed choline peak were osteosarcoma $(n=4)$, chondrosarcoma $(n=1)$, metastasis from breast, and renal cell carcinoma $(n=2)$. Amongst osteosarcomas, tall choline peak was seen in conventional osteosarcoma (Fig. 1a-c). Small choline peak was observed in telangiectatic osteosarcoma probably due to intra-tumoral large cystic areas (Fig. 2a-d). One chondrogenic osteosarcoma with low histological grade also showed a small choline peak (Fig. 3a-c). However, we did not perform any quantitative analysis of choline or assess its correlation with the histological grade of the tumor. Spectrum in one case of parosteal osteosarcoma was inadequate due to noise, possibly because of large amount of osteoid which could not be excluded from the voxel. One case of chondrosarcoma also showed a tall choline peak (Fig. 4).

Choline peak was absent in 27/38 benign lesions. Choline peak was absent in 6 out of 7 benign cartilaginous tumors including osteochondroma $(n=5)$ (Fig. 5a, b) and juxta-corticalchondroma $(n=1)$.

Choline peak was absent in one case diagnosed as osteosarcoma on plain radiograph due to the presence of permeative lytic destruction and Codman's triangle. The conventional MRI did not alter the diagnosis made on
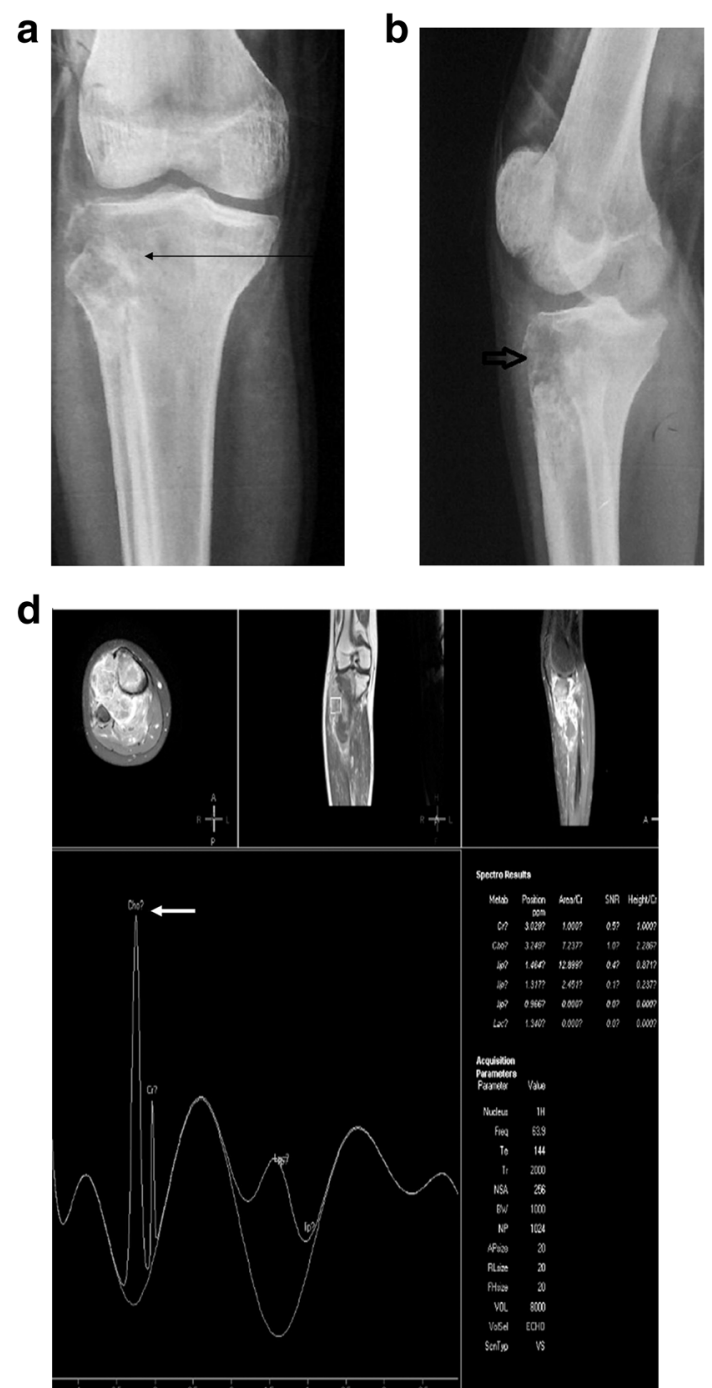

C

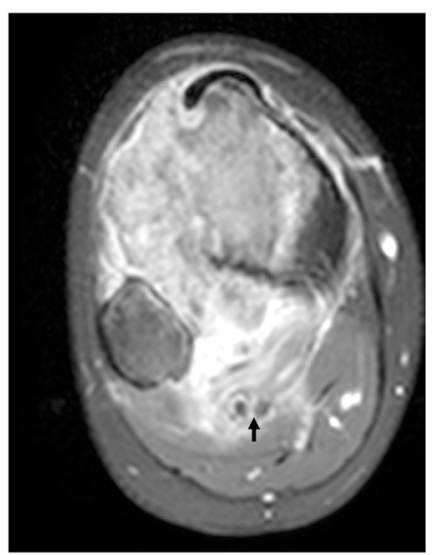

e

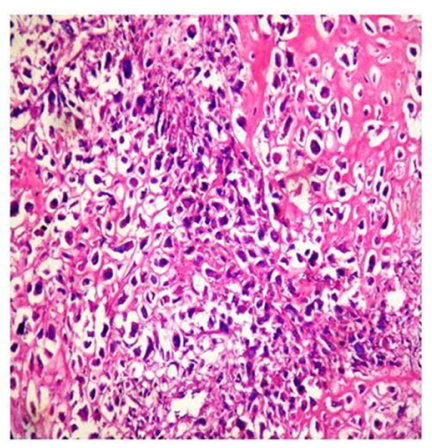

Fig. 121 -year-old male patient. a. AP radiograph of the right knee. Irregular lytic lesion (black arrow) in the right proximal tibial epimetaphysis (arrow). b. Lateral radiograph of the right knee. The lesion is more conspicuous and shows cortical destruction (arrow). c. Post-contrast T1weighted axial image showing large destructive lesion with peripheral contrast enhancement. The associated soft tissue is causing popliteal vessel encasement (arrow). d. MRS shows a tall choline peak at 3.2 ppm (arrow). e. HNE 200x showing highly atypical stromal cells laying down osteoid suggestive of osteosarcoma 
a

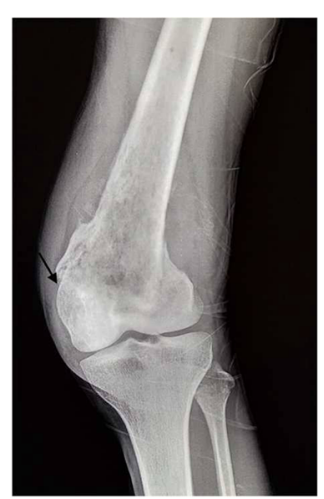

d

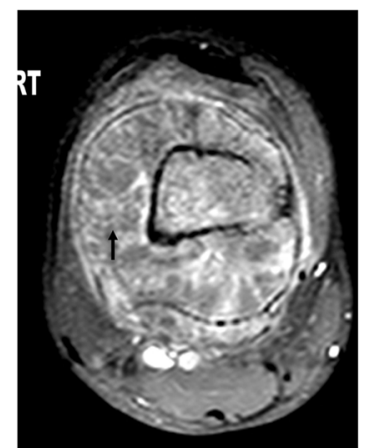

f

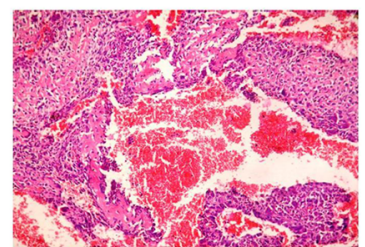

b

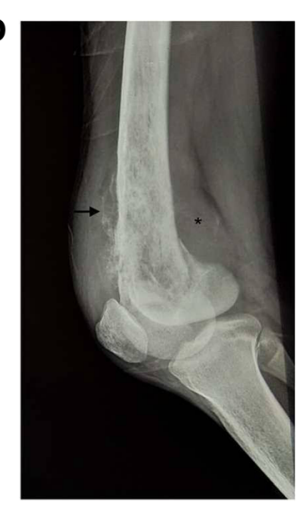

C

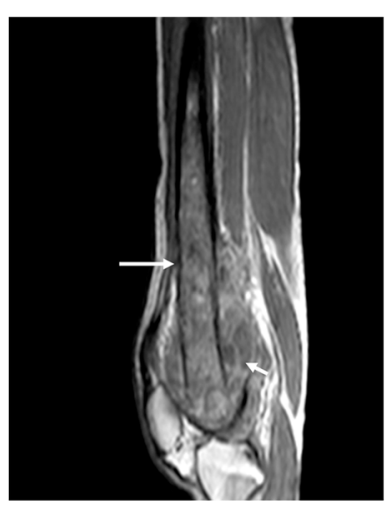

e

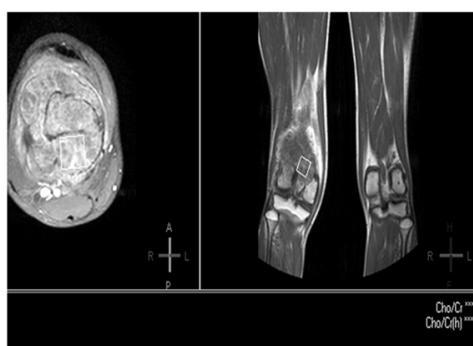

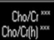

Spectro Results

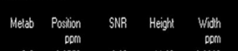

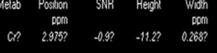

Chas? 3162? 0.9P 11.5? 0.026?

$16 \quad \begin{array}{llll}1.34 & 55 & 695 & 0.24\end{array}$

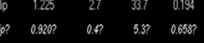

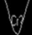

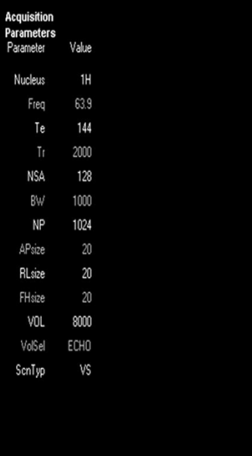

Fig. 2 An18-year-old male patient with swelling and pain right knee. a. AP radiograph of right knee. Permeative lysis is seen in the right distal femoral metaphysis with pathological fracture (arrow). b. Lateral radiograph of right knee. Interrupted type of periosteal reaction is evident with Codman's triangle (arrow) and soft tissue component (asterisk). c. Post contrast T1 weighted sagittal image. Distal femoral metadiaphyseal destructive lesion with cortical erosion (long arrow) and soft tissue mass denoted by (short arrow). d. Post contrast fat saturated T1 weighted axial image. Thick irregular nodular enhancing septae (arrow), are seen interspersed with numerous non enhancing cystic areas. e. MRS shows small Choline peak at 3.2 ppm (arrow). f. HNE100X showing multiple cystic spaces containing blood lying by cyst wall showing presence malignant cells along with osteoid and giant cells suggestive of telangiectatic osteosarcoma

radiograph. However, the lesion showed the absence of choline peak on ${ }^{1}$ HMRS. The diagnosis of osteomyelitis was made histologically (Fig. 6a-c).

As choline peak was observed both in benign and malignant bone lesions. Therefore the absence of choline peak is a significant factor to differentiate benign from malignant bone lesions. The negative predictive value in our study was $96.2 \%$.
All cases of GCT $(n=7)$ showed choline peak (Fig. $7 \mathrm{a}-\mathrm{d}$ ). The choline peak was present irrespective of aggressive or benign histopathological appearance of GCT.

Amongst other benign lesions, choline peak was present in one case of CMF (Fig. 8a-c) and in 3 out of 18 cases of infective osteomyelitis including one case of tubercular osteomyelitis and another of Brodie's abscess. 

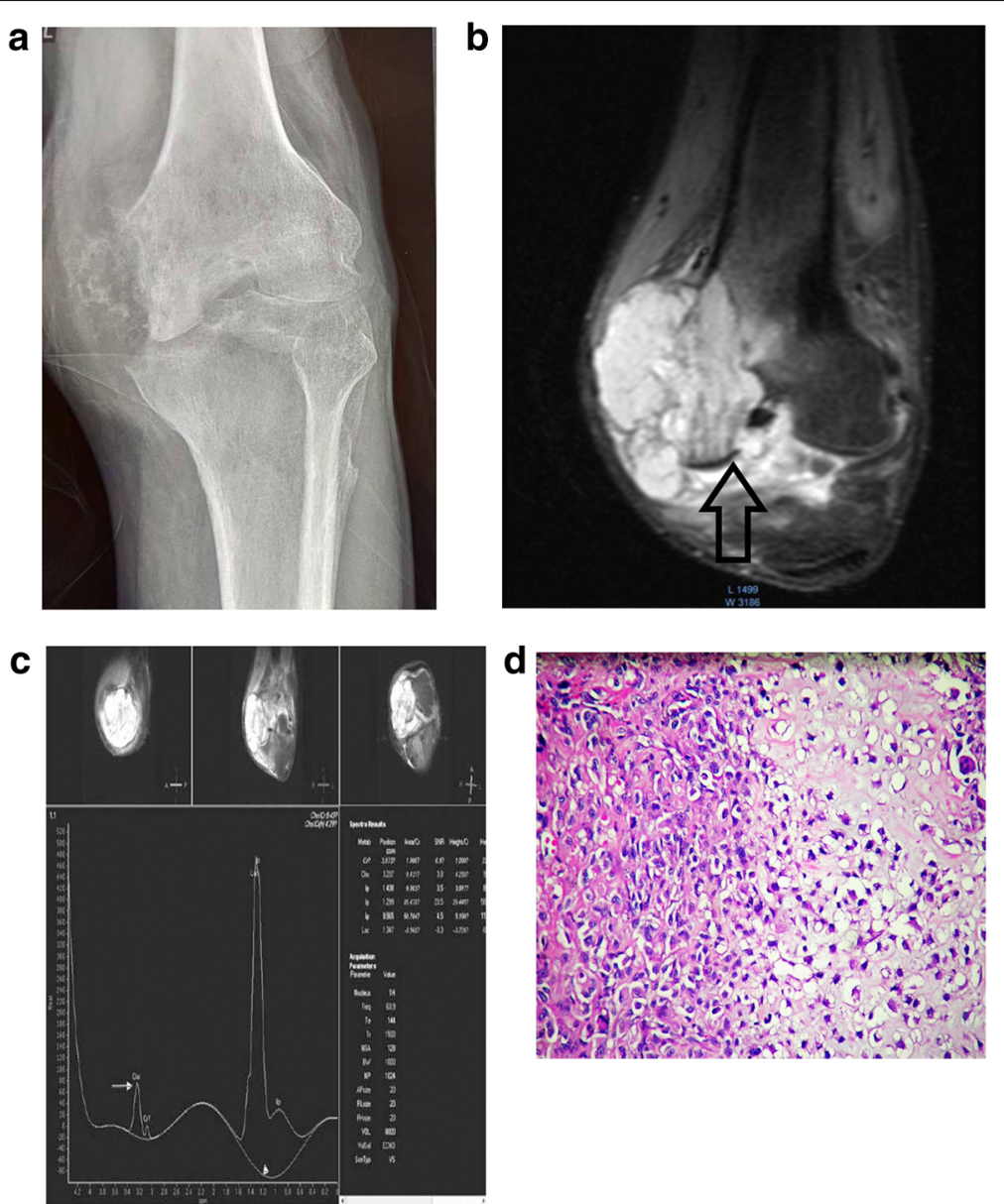

Fig. 3 A 22-year-old male patient with swelling in the left knee. a AP radiograph of the left knee. Lytic destruction (arrow) of medial femoral condyle with erosion of medial tibial plateau. b STIR image shows an eccentric hyper intense epimetaphyseal destructive lesion with soft tissue mass in the distal femur (arrow). c MRS shows discrete small choline peak at $3.2 \mathrm{ppm}$. d HNE 200× show lobules of malignant cartilage with spindling at the periphery and osteoid formation suggestive of chondrogenic osteosarcoma

Applying the chi-square test in determining the significance of proton MR spectroscopy in differentiating benign from malignant lesions, the $p$ value obtained was $<0.005(<.05)$, which is significant. The sensitivity, specificity, PPV, NPV of proton MR spectroscopy in differentiating benign from malignant lesions was $87.5 \%, 71 \%, 38.8 \%$, and $96.4 \%$ respectively (Table 2 ). The bsence of choline peak was the most significant factor to rule out a malignant lesion, while the presence of choline peak was seen in many benign lesions. In particular, all GCTs showed a discrete choline peak. Since choline peak was present in all the cases of GCT, we re-analyzed the data considering choline peak in GCT as a true positive finding (Table 3). Applying chi-square test the $p$ value calculated is $<0.001$, while the sensitivity, specificity, PPV, and NPV are 93.3\%, 86.6\%, 77.7\%, and $96.2 \%$ respectively.

\section{Discussion}

MR spectroscopy is an established modality for providing metabolic information of lesions and detection of choline which is a marker for cell division and hence frequently present in malignant lesions [6, 7].

MRS in bone lesions is different from MRS in the brain, prostate, or breast lesions. The inherent heterogeneity due to muscle, fat, vessels, and osseous trabeculae as well as magnetic susceptibility in bone makes adequate shimming a daunting task. There is a high probability of getting inadequate spectrum due to contamination by lipids which are abundantly present in musculoskeletal system [4]. Also, abundant creatine in muscle can mask the smaller metabolites. Coil selection is also a challenge in bone MR spectroscopy the most appropriate coil according to the part of interest should be applied, with a preference for surface coil wherever possible. 
a

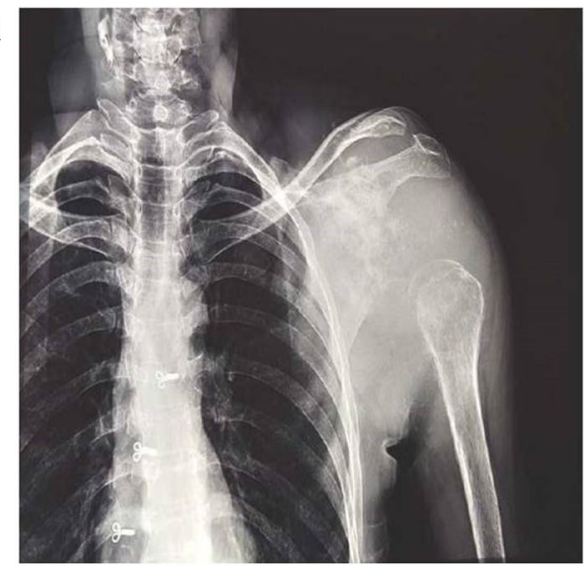

b

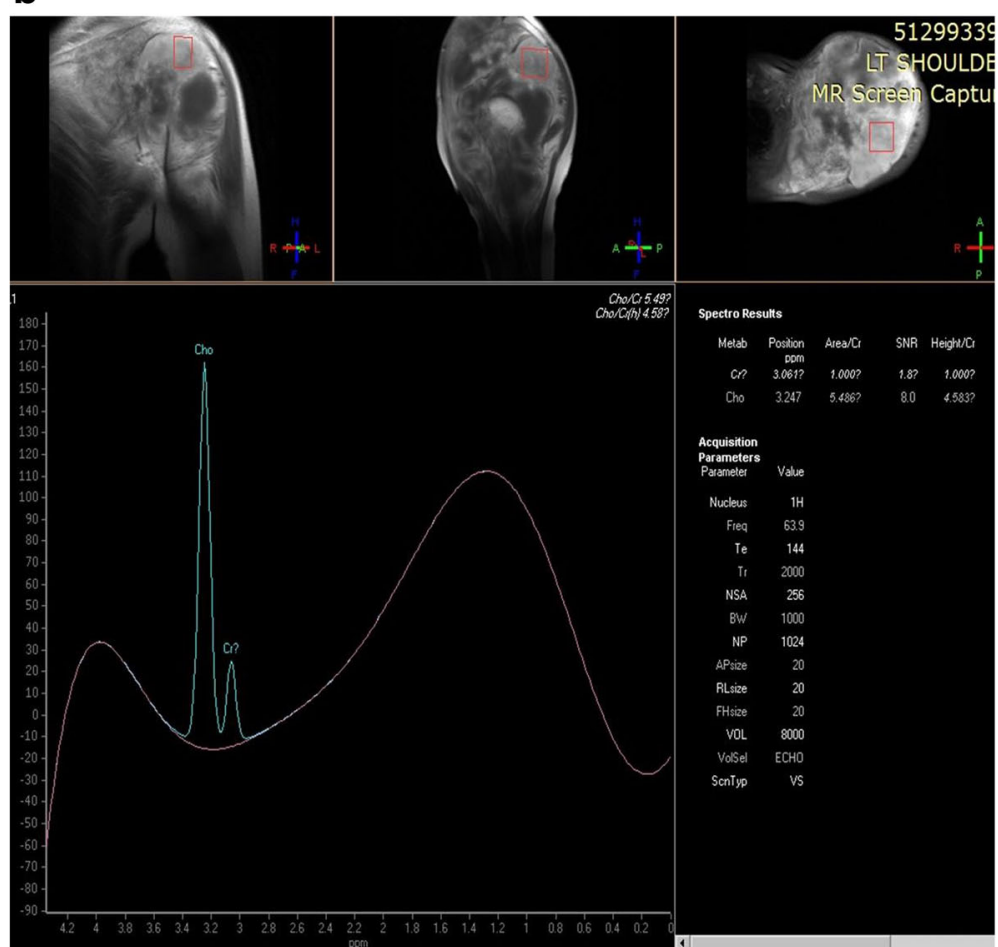

Fig. 4 A 42-year-old female patient with swelling in left shoulder joint. a AP radiograph of left shoulder. Lytic destruction of scapular glenoid extending into the shoulder joint with the involvement of humerus (arrow), large soft tissue component is seen with calcifications (open arrow). b MRS shows choline peak at $3.2 \mathrm{ppm}$. HPE confirmed chondrosarcoma

We performed single voxel ${ }^{1}$ HMRS. Multivoxel spectroscopy requires large shimming volumes to reduce the magnetic susceptibility artifacts, making the examination further technically challenging $[6$, 8]. Single voxel spectroscopy provides higher SNR and less interference from other metabolite peaks. We have used automatic shimming in our study in order to simplify the examination as we were assessing the feasibility of routine clinical use. Although manual shimming has been advocated in earlier studies [9], more recent studies have used automatic shimming [6]. We used a criterion of good symmetric water spectral profile after shimming to judge the adequacy of B0 field homogeneity. We performed the examination using a single-intermediate TE value of $144 \mathrm{~ms}$. Unlike the brain, a large amount of lipid is present in bone. At an intermediate TE, lipid signal is reduced owing to its shorter $\mathrm{T} 2$ and is less likely to interfere with neighboring peaks than at a shorter TE [10]. 
a
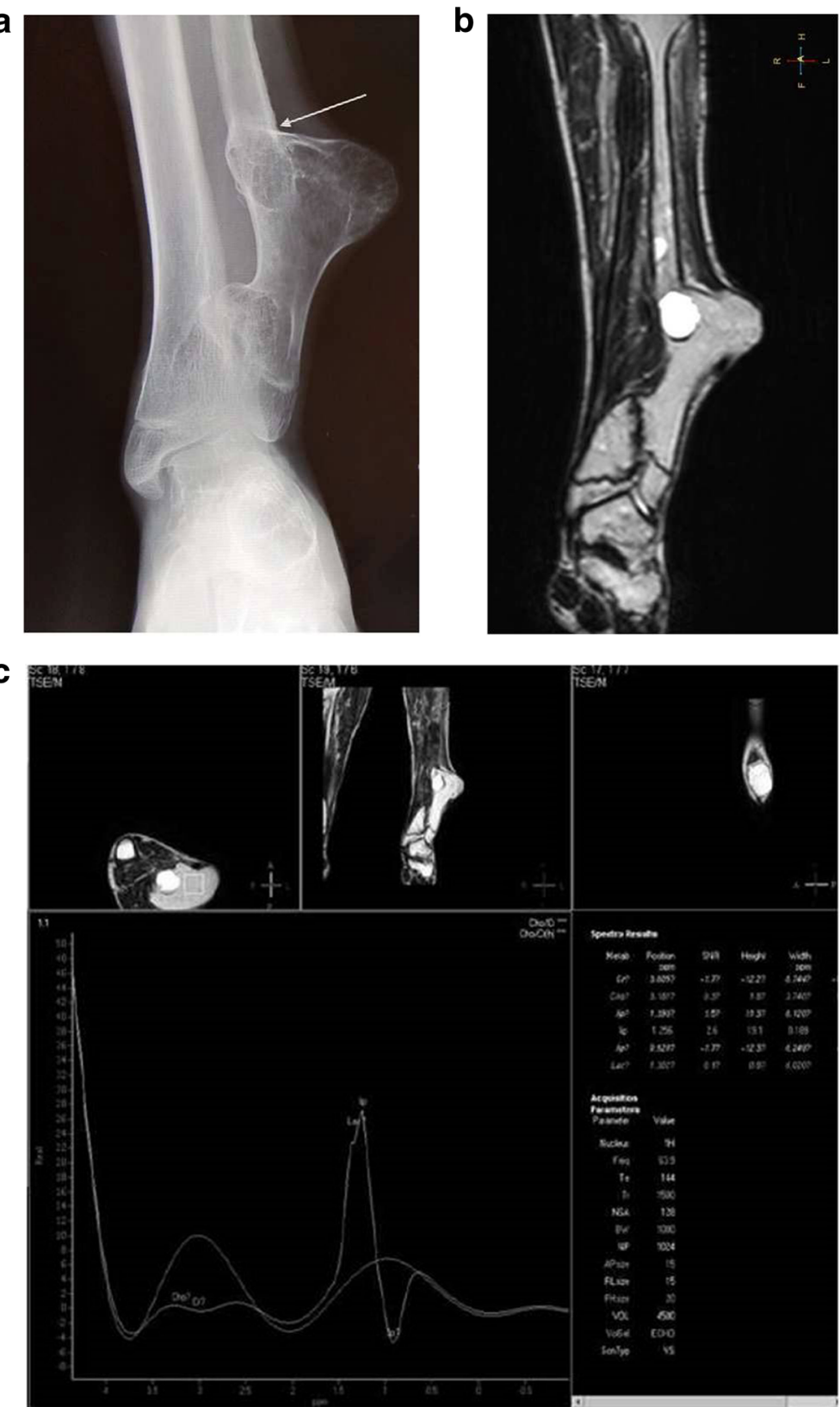

b

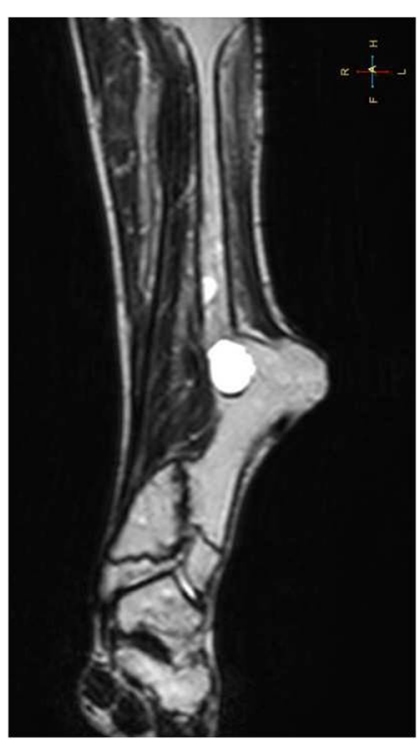

Fig. 5 A 12-year-old male patient with bony hard swelling left leg. a Radiograph showing a bony outgrowth (arrow) in the distal left fibula with medulla and cortex continuous with that of the parent bone suggestive of osteochondroma fibula is deformed. $\mathbf{b}$ STIR image shows a bony outgrowth in a deformed fibula with medulla and cortex continuous with that of the parent bone. A cystic area is seen at the base of the lesion. c MRS shows no choline peak

Like in MRS of other body parts, voxel selection should avoid necrotic, cystic areas in a lesion. The area showing maximum enhancement should be taken for the voxel placement to achieve adequate and correct spectrum. Technically, adequate spectra were obtained in 46/50 (92\%) patients in our study.

Only one malignant case in our study which was a low-grade lymphoma (non-Hodgkin's lymphoma, B cell type) did not show choline peak. Choline peak occurrence has a correlation with the histological grade of the bone tumor [11]. Our results are also supported by those of Patni.et.al in 2017 [12].

The behavior of GCT on ${ }^{1}$ HMRS merits some elaboration. GCT consistently showed the presence of choline peak in all the 7 cases with technically adequate spectra in our study. Choline peaks have been found in previous 
a
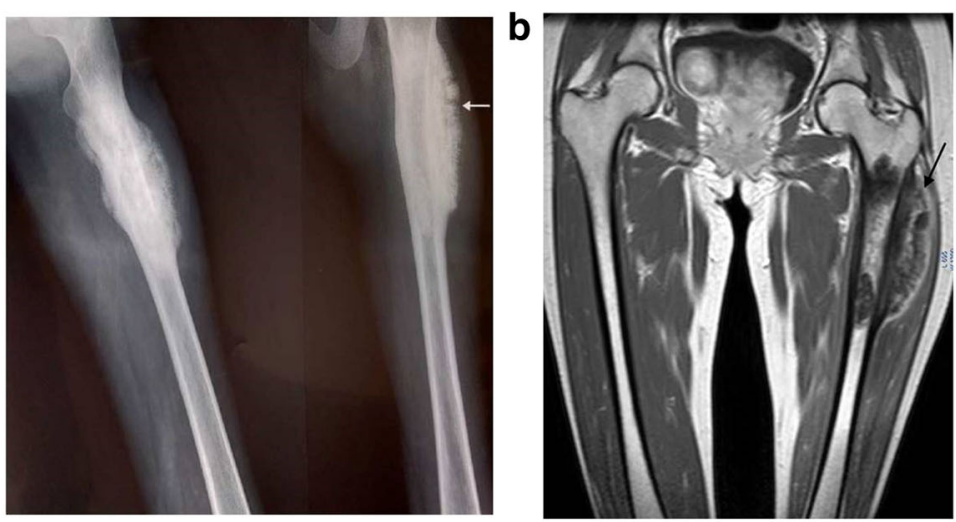

C
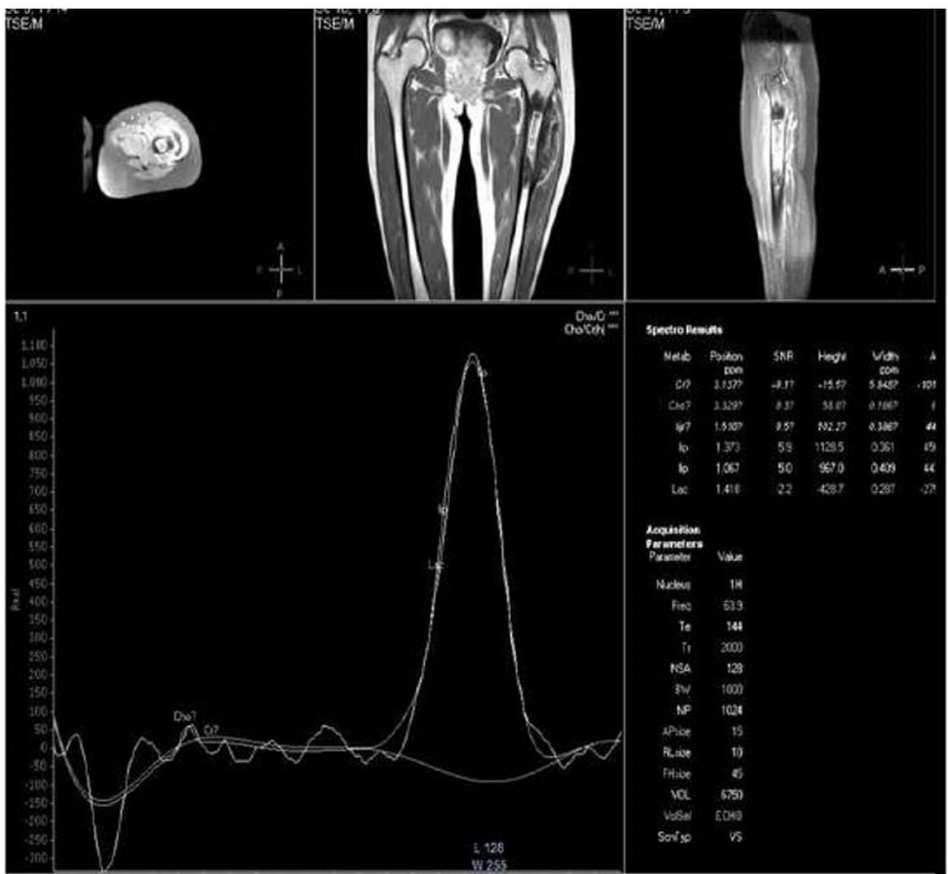

Fig. 6 A 17-year-old female patient with pain in the left thigh. a Radiograph showing a dense sclerotic lesion in the metaphysis of the left proximal femur with an apparent sun-burst type of periosteal reaction along the lateral aspect (arrow) and matrix ossification. The radiographic diagnosis was osteosarcoma. $\mathbf{b}$ Coronal T1-weighted post-contrast image shows metaphyseal lesion with a radiating type of periosteal reaction (arrow). Contrast enhancement is seen within the periosteal component. c MRS shows no discrete choline peak. A tall lipid lactate peak is noted. Histopathology was proven to be chronic osteomyelitis

studies in malignant hypercellular GCTs as well as benign GCTs with proliferative activity. Sah et al. conducted ${ }^{1} \mathrm{H}$ MRS on 12 patients with GCT and found a discrete choline peak in 4 of these. They found a definite correlation between the radiologic and histological grade of GCT and choline peak [9]. Zhang et al. found 20\% $(n=4 / 20)$ cases of GCT in their study showed a cho/ lipid ratio $\geq 0.2$, which was their criteria under evaluation for malignant versus benign bone tumors [6]. Contrary to Sah et al., they found no histological aggressiveness in these four tumors. Our study is in partial concordance with literature because we found choline peak in 100\% cases of GCT irrespective of the presence of choline peak with an aggressive or benign appearance on histology or plain radiograph. The variable results in different studies warrant further investigation in the subject.

Choline peak was absent in 6 out of 7 benign cartilaginous tumors. One case of chondromyxoid fibroma showed a small choline peak. However, choline peak was not detected in spectra from other benign cartilaginous tumors like osteochondromas and juxtacorticalchondroma in our study. The radiological differentiation of enchondroma from low-grade chondrosarcoma is difficult on plain radiography, CT, and even conventional 
a

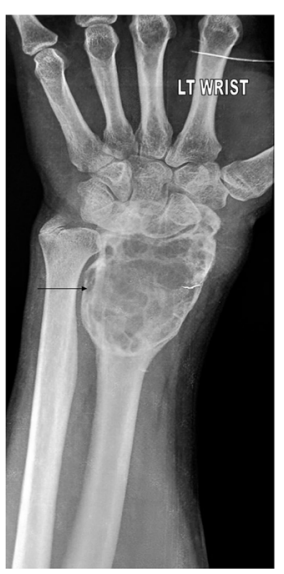

b

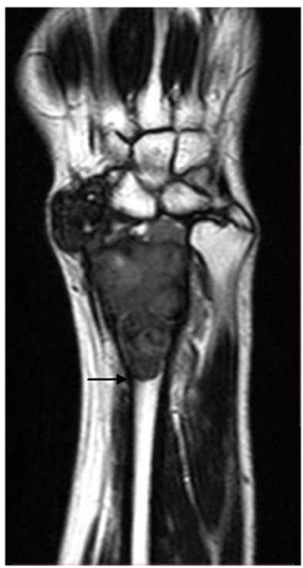

C
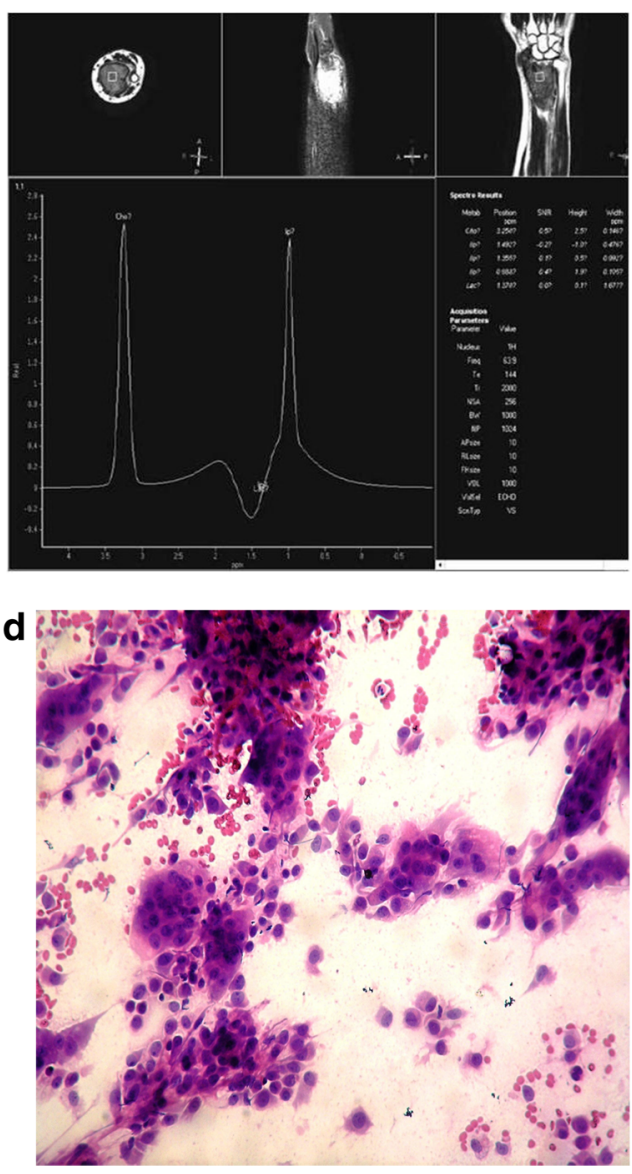

Fig. 7 A30-year-old male patient with pain and swelling left wrist. a Radiograph shows subarticular left distal radial lesion with characteristic soap bubble appearance (arrow) suggestive of GCT. Radial cortex is intact. $\mathbf{b}$ The lesion is hypointense on T2-weighted coronal image, with the distinct transition from normal marrow (arrow). c MRS shows a tall choline peak at $3.2 \mathrm{ppm}$. $\mathbf{d}$ HNE 200X shows fragments of neoplastic stromal cells and numerous multinucleate giant cells suggesting GCT

MRI [1]. Advanced MRI techniques have also shown mixed patterns. The high chondroid matrix content facilitates diffusion resulting in high ADC values even in malignant cartilaginous tumors. Perfusion or dynamic contrast MRI may be able to differentiate chondrosarcoma from inactive enchondroma but not from active enchondroma which can show rapid enhancement. The absence of choline peak on ${ }^{1}$ HMRS in a radiologically indeterminate cartilaginous tumor may add diagnostic specificity to a multiparametric MRI examination.

Choline peak was also present in few $(n=3)$ infective osteomyelitis including one case of tubercular osteomyelitis. Earlier studies have also detected choline peak in inflammatory lesions [5] and has been attributed to the proliferation of inflammatory cells.

A summary of previous studies done on the subject and their comparison with our results is given in Table 4. Our results are in general agreement with many previous studies $[3,5,7,9,12-16]$. Some researchers have obtained a higher specificity and PPV which may be due to the inclusion of higher proportion of malignant tumors and more soft tissue tumors or quantification methods [3, 7]. Sensitivity was lower in some studies possibly due to stricter criteria for positive result $[3,15,16]$.

Most researchers concluded that ${ }^{1}$ HMRS may be a useful tool for differentiation between benign and malignant musculoskeletal lesions. Low-grade malignant tumors and GCT, acute inflammatory lesions were commonly responsible for false-negative and falsepositive result respectively. Benign lesion with hypercellularity, hypervascularity, and large number of inflammatory cells could present with positive choline peak. Osteoid, cystic areas, necrosis, and small voxel size were common issues responsible for a technical failure or false results.

Teixerai PAC et al. in 2017 [17] differ in their recommendation form most previous studies. They concluded 


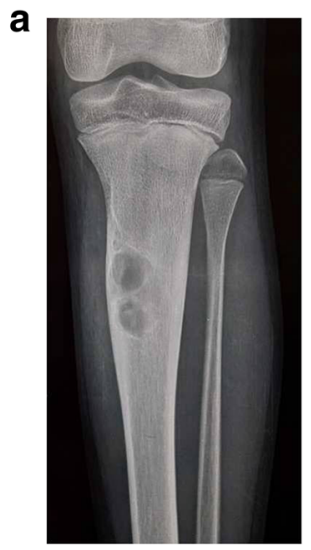

b

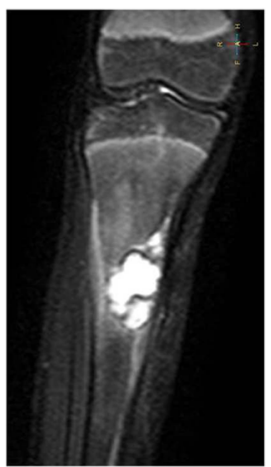

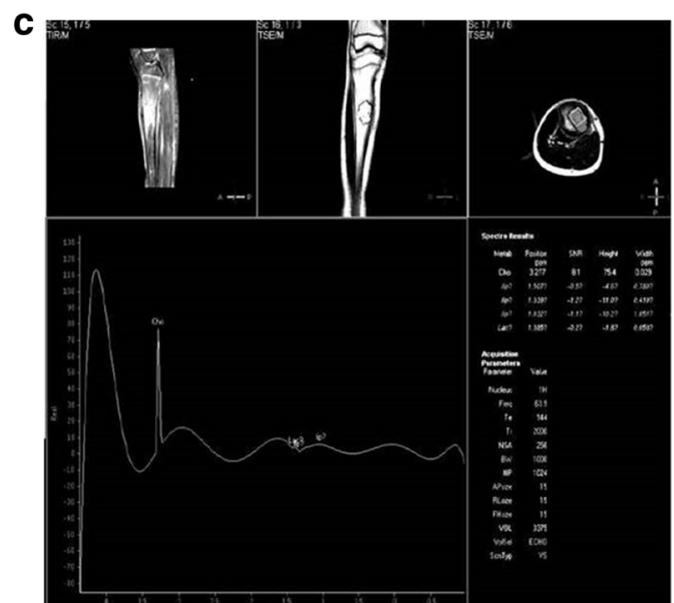

d

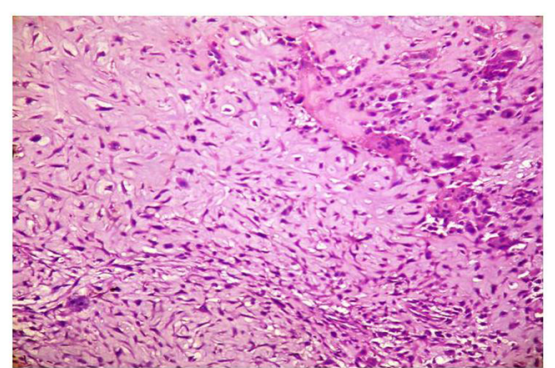

Fig. 8 A 13-year-old male patient with pain in the right leg. a. AP radiograph of the left leg. A geographical metaphyseal lytic lesion (arrow) having a thin sclerotic rim suggestive of a benign lesion. $\mathbf{b}$ STIR coronal image shows a well defined hyperintense eccentric metaphyseal lesion in right tibia. c MRS shows choline peak at 3.2 ppm. d HNE 200x shows lobule of myxoid material with stellate cells displaying hypercellularity at the periphery along with giant cells diagnostic of chondromyxoid fibroma

that MRS cannot be used to characterize bone tumors. However, their sample included 28 bone tumors, out of which 15 were malignant and 13 were benign. Six out of 15 malignant tumors were low-grade chondrosarcomas and 7 out of 13 benign tumors were GCT. We speculate that their sample selection bias may be a reason for differing results.

There were many limitations to our study. We performed ${ }^{1} \mathrm{HMRS}$ on $1.5 \mathrm{~T}$ MRI scanner. High magnetic strengths may result in better quality spectra with higher SNR. The number of malignant lesions in our study was small. In many other previous studies, the ratio of malignant and benign lesions was not so unequal $[4,6]$. This was because we included consecutive patients on the basis of radiography findings.

Table 2 Table for the significance of the presence of choline peak in benign and malignant lesions ( $p$ value $<0.005$ )

\begin{tabular}{lll}
\hline Choline & Malignant & Benign \\
\hline Present & True positive $=7$ & False positive $=11$ \\
Absent & False-negative $=1$ & True negative $=27$ \\
\hline
\end{tabular}

The sample size in our study was apparently small with 50 cases. However, we examined only bone tumors and no soft tissue tumors were included. MRS in soft tissue tumors is not as challenging as in bone tumors. Most of the previous literature included both bone and soft tissue tumors. Further, we studied lesions only in the appendicular skeleton which were easily approachable for histopathological sampling. To the best of our knowledge, the largest available data on musculoskeletal MRS till date is a review of a pooled analysis using 122 cases of both soft tissue and bone tumors [4]. The distribution of benign and malignant tumors in this pooled analysis was nearly equitable. Forty-eight out of 122 cases in their study were bone tumors. Only one research study by Zhang

Table 3 Significance of choline peak in differentiating malignant lesions and GCT from benign lesions ( $p$-value< 0.001 )

\begin{tabular}{lll}
\hline Choline & Malignant lesions+ GCT & Benign lesions \\
\hline Present & True positive $=14$ & False positive $=4$ \\
Absent & False-negative $=1$ & True negative $=27$ \\
\hline
\end{tabular}


Table 4 Showing results and comparison of previous studies

\begin{tabular}{|c|c|c|c|c|c|c|}
\hline Ref. no. & $\begin{array}{l}\text { Sample } \\
\text { size }\end{array}$ & Inclusions & $\begin{array}{l}\text { SVS/ } \\
\text { MVS, } \\
\text { TE (ms) } \\
\text { Scanner }\end{array}$ & $\begin{array}{l}\text { Choline } \\
\text { quantification } \\
\text { method }\end{array}$ & Results & $\begin{array}{l}\text { Comparison with the } \\
\text { present study }\end{array}$ \\
\hline $\begin{array}{l}\text { Aggarwal S } \\
\text { et al. } 2014 \text { (3) }\end{array}$ & 30 & $\begin{array}{l}\text { Bone and soft } \\
\text { tissue lesions, } \\
\text { mainly soft tissue } \\
\text { masses }\end{array}$ & $\begin{array}{l}\text { SVS } \\
40,135 \\
270 \\
1.5 \mathrm{~T}\end{array}$ & $\begin{array}{l}\text { Cho/SNR }>2 \text { in } \\
\text { at least two TEs }\end{array}$ & $\begin{array}{l}\text { Sensitivity } 60 \% \\
\text { Specificity } 93.3 \% \\
\text { PPV } 90 \% \\
\text { NPV } 70 \% \\
\text { Accuracy } 76.6 \% \\
\text { Concluded that MRS is a promising } \\
\text { adjunct tool. }\end{array}$ & Similar conclusions. \\
\hline $\begin{array}{l}\text { Wang et al. } \\
2004 \text { (5) }\end{array}$ & 36 & $\begin{array}{l}\text { Both bone (15) and } \\
\text { soft tissue (21) } \\
\text { masses }\end{array}$ & $\begin{array}{l}\text { SVS } \\
40,135 \\
270 \\
1.5 T\end{array}$ & $\begin{array}{l}\text { Qualitative, } \\
\text { choline peak on } \\
\text { spectra at least } \\
\text { two TEs }\end{array}$ & $\begin{array}{l}\text { Choline found in 18/19 malignant } \\
\text { tumors. } \\
\text { Sensitivity } 95 \% \\
\text { Specificity } 82 \%\end{array}$ & Very similar results \\
\hline $\begin{array}{l}\text { Zhang et al. } \\
2013(6)\end{array}$ & 83 & Only bone tumors & $\begin{array}{l}\text { SVS } \\
110 \\
1.5 T\end{array}$ & $\begin{array}{l}\text { Semiquantitative } \\
\text { Cho:lipid ratio } \geq \\
0.2 \text { was positive } \\
\text { result }\end{array}$ & $\begin{array}{l}\text { Concluded that MRS can help in } \\
\text { differentiating benign and malignant } \\
\text { bone tumors. } \\
\text { Sensitivity } 76 \% \\
\text { Specificity } 88 \%\end{array}$ & Similar conclusions. \\
\hline $\begin{array}{l}\text { Zi-Hua Ql } \\
\text { et al. } 2009 \text { (7) }\end{array}$ & 56 & $\begin{array}{l}\text { Both bone and soft } \\
\text { tissue tumors }\end{array}$ & $\begin{array}{l}\text { SVS } \\
144 \\
3 T\end{array}$ & $\begin{array}{l}\text { Semi- } \\
\text { Quantitative, } \\
\text { Cho/Cr ratios }\end{array}$ & $\begin{array}{l}\text { Cho/Cr ratios were significantly } \\
\text { higher in malignant lesions. } \\
\text { Sensitivity } 94 \% \\
\text { Specificity } 83 \% \\
\text { PPV } 92 \% \\
\text { NPV } 88 \%\end{array}$ & $\begin{array}{l}\text { Sensitivity, specificity similar. } \\
\text { PPV, NPV probably different } \\
\text { because of the semi- } \\
\text { quantitative method. }\end{array}$ \\
\hline $\begin{array}{l}\text { Fayad LM, } \\
\text { Wang X et al. } \\
2010 \text { (9) }\end{array}$ & 34 & $\begin{array}{l}\text { Bone and soft } \\
\text { tissue lesions. }\end{array}$ & $\begin{array}{l}\text { SVS } \\
135 \\
3 T\end{array}$ & $\begin{array}{l}\text { Quantitative, } \\
\text { Cho } \\
\text { concentrations } \\
\text { calculated }\end{array}$ & $\begin{array}{l}\text { Choline present in all } 3 \text { pre-treatment } \\
\text { malignant lesions. } \\
\text { Choline concentration was } \\
\text { different in benign and malignant. }\end{array}$ & Similar results. \\
\hline $\begin{array}{l}\text { Patni.et. } \\
\text { al.2017 } \\
(12)\end{array}$ & 42 & $\begin{array}{l}\text { Patients } \\
\text { undergoing MRI for } \\
\text { musculoskeletal } \\
\text { tumors }\end{array}$ & $\begin{array}{l}\text { MVS } \\
135\end{array}$ & Quantitative & $\begin{array}{l}\text { Cho/Cr ratios were significantly } \\
\text { higher in malignant lesions. }\end{array}$ & $\begin{array}{l}\text { Statistical significance seen } \\
\text { between Cho/Cr ratio and } \\
\text { histological grade of the } \\
\text { tumor. }\end{array}$ \\
\hline $\begin{array}{l}\text { Fayad LM, } \\
\text { Blumke DA } \\
\text { et al. } 2006 \\
\text { (13) }\end{array}$ & 13 & $\begin{array}{l}\text { Resected } \\
\text { specimens of bone } \\
\text { sarcomas }\end{array}$ & $\begin{array}{l}\text { MVS } \\
280 \\
1.5 \mathrm{~T}\end{array}$ & $\begin{array}{l}\text { Semi- } \\
\text { quantitative } \\
\text { Cho/SNR ratio }\end{array}$ & $\begin{array}{l}\text { All bone sarcomas showed choline } \\
\text { peak which was much higher than } \\
\text { normal marrow. }\end{array}$ & $\begin{array}{l}\text { Similar results, Concluded that } \\
\text { choline can be used as a } \\
\text { marker for malignancy in bone } \\
\text { tumors. }\end{array}$ \\
\hline $\begin{array}{l}\text { Fayad LM, } \\
\text { Barker PB } \\
2006(14)\end{array}$ & $\begin{array}{l}23 \\
\text { lesions } \\
\text { in } 18 \\
\text { patients }\end{array}$ & $\begin{array}{l}\text { Bone (6 patients) } \\
\text { and soft tissue } \\
\text { lesions ( } 12 \\
\text { patients) }\end{array}$ & $\begin{array}{l}\text { SVS } \\
(20)+ \\
\text { MVS(3) } \\
144 \\
3 T\end{array}$ & $\begin{array}{l}\text { Semiquantitative, } \\
\text { Cho/SNR ratios }\end{array}$ & $\begin{array}{l}\text { Choline peak present in all pretreatment } \\
\text { malignant cases. } \\
\text { Mean Cho/SNR ratios in malignant and } \\
\text { benign lesions was different }\end{array}$ & Similar results. \\
\hline $\begin{array}{l}\text { Lee CW et al. } \\
2009 \\
(15)\end{array}$ & 27 & $\begin{array}{l}\text { Both bone and soft } \\
\text { tissue tumors. } \\
19 \text { malignant and } 8 \\
\text { benign lesions. }\end{array}$ & $\begin{array}{l}\text { SVS } \\
144 \\
3 T\end{array}$ & $\begin{array}{l}\text { Quantitative } \\
\text { Cho } \\
\text { concentration } \\
\text { calculated. }\end{array}$ & $\begin{array}{l}\text { Sensitivity } 68.4 \% \\
\text { Specificity } 87.5 \% \\
\text { Concluded that low-grade malignancies } \\
\text { have a may false-negative result on MRS }\end{array}$ & Similar conclusions \\
\hline $\begin{array}{l}\text { S. Doganay } \\
\text { et al. } 2011 \\
\text { (16) }\end{array}$ & 30 & $\begin{array}{l}\text { Bone or soft tissue } \\
\text { tumors. }\end{array}$ & $\begin{array}{l}\text { SVS } \\
31,136 \\
272 \\
1.5 T\end{array}$ & $\begin{array}{l}\text { Qualitative } \\
\text { Cho peak on } \\
\text { spectra from at } \\
\text { least two TEs }\end{array}$ & $\begin{array}{l}\text { Concluded that MRS may be a useful } \\
\text { tool. } \\
\text { Sensitivity } 72.2 \% \text {. } \\
\text { Specificity } 83.3 \%\end{array}$ & Similar conclusions. \\
\hline $\begin{array}{l}\text { Teixeria PAG } \\
\text { et al. } \\
2017 \\
(17)\end{array}$ & $\begin{array}{l}76 \\
\text { lesions } \\
\text { in } 74 \\
\text { patients }\end{array}$ & $\begin{array}{l}\text { Both bone and soft } \\
\text { tissue tumors. } \\
28 \text { bone tumors, } 15 \\
\text { malignant. }\end{array}$ & $\begin{array}{l}\text { SVS } \\
144 \mathrm{TE} \\
3 \mathrm{~T}\end{array}$ & Qualitative & $\begin{array}{l}\text { Did not recommend MRS for } \\
\text { characterization. } \\
\text { Sensitivity } 46.7 \% \\
\text { Specificity } 61.5 \% \\
\text { For bone tumors. }\end{array}$ & $\begin{array}{l}\text { Different results. } \\
\text { Selection bias possible }\end{array}$ \\
\hline
\end{tabular}

et al. has a larger sample size of 83 patients with bone tumors. In their study, 34 tumors were benign while 49 were malignant.

Overall, our study is important because of the large sample size for the exclusive study of bone lesion
${ }^{1}$ HMRS. Our sample was consecutive inclusion of patients based on radiography findings, thereby excluding any selection bias and giving more clinically relevant data. We attempted to analyze if a simple qualitative ${ }^{1}$ HMRS on $1.5 \mathrm{~T}$ scanner done within a reasonable time 
limit with single TE and automatic shimming is useful in characterization. Our results indicate that MRS can be used as a complementary tool in a multiparametric MRI examination for bone tumor characterization.

\section{Conclusion}

${ }^{1} \mathrm{H}$ MRS of focal bone lesions is a valuable modality which can be used for differentiation between benign and malignant bone lesions. The absence of choline peak in solid areas of the tumor is a significant marker to rule out malignant lesions. GCT is an exception amongst benign neoplasms which consistently shows the presence of choline peak. Further studies could be done to evaluate the benefit of choline quantification, correlation with histological tumor grade and assessment of treatment response.

\section{Abbreviations \\ 1HMRS: Proton MR spectroscopy; ADC: Apparent diffusion coefficient; CMF: Chondromyxoid fibroma; GCT: Giant cell tumor; NPV: Negative predictive value; PPV: Positive predictive value; PRESS: Point-resolved spectroscopy sequence; SNR: Signal to noise ratio}

\section{Acknowledgements}

None.

\section{Involvement of animals}

Not applicable.

\section{Authors' contributions}

RG designed the study and had an important role in the analysis and interpretation of data. MA contributed to the analysis and interpretation of data. LK, as per his expertise as an orthopedician, has referred the patients for the study, and had an important role in examining the patients and providing surgical treatment to these patients. GK, as per her expertise as a pathologist in orthopedics department, had an important role in providing the final histopathological diagnosis. All authors have read and approved the manuscript. All authors agree with the submitted version. All authors have agreed both to be personally accountable for the author's own contributions and to ensure that questions related to the accuracy or integrity of any part of the work, even ones in which the author was not personally involved, are appropriately investigated, resolved, and the resolution documented in the literature.

\section{Funding}

nil

\section{Availability of data and materials}

The datasets used and/or analyzed during the current study are available from the corresponding author on reasonable request.

\section{Ethics approval and consent to participate}

The study was given clearance by the ethical committee of our institution with S.No.IECNMMC/SJH/Thesis/November-2014/412.

Informed written consent to participate in the study was taken from the patients prior to investigation. In the case of minors, consent was obtained from their parents.

\section{Consent for publication}

Informed written consent for publication of data was obtained from all participants in the study. In the case of minors, consent was obtained from their parents.

\section{Competing interests}

The authors declare that they have no competing interests.

\section{Author details}

'Department of Radiodiagnosis, VMMC \& Safdarjung hospital, New Delhi 110029, India. ${ }^{2}$ Department of Orthopedics, VMMC and Safdarjung hospital, New Delhi, India. ${ }^{3}$ Central Institute of Orthopedics (CIO pathology lab), VMMC and Safdarjung Hospital, New Delhi, India.

Received: 28 November 2019 Accepted: 5 December 2019

Published online: 17 December 2019

\section{References}

1. Costa F, Canella C, Gasparetto E (2011) Advanced magnetic resonance imaging techniques in the evaluation of musculoskeletal tumors. Radiol Clin North Am 49:1325-1358. https://doi.org/10.1016/j.rcl.2011.07.014

2. Mansfield P, Maudsley A (1976) Line scan proton spin imaging in biological structures by NMR. Phys Med Biol 21:847-852. https://doi.org/10.1088/00319155/21/5/013

3. Aggarwal S, Kundu Z, Kumar S, Sangwan S (2014) Single voxel1H magnetic resonance spectroscopy in the diagnosis of musculoskeletal mass lesions. Clin Cancer Investig J 4:66. https://doi.org/10.4103/2278-0513.125800

4. Subhawong T, Wang X, Durand D, Jacobs M, CarrinoJ MA et al (2012) Proton MR spectroscopy in metabolic assessment of musculoskeletal lesions. AJR 198:162-172. https://doi.org/10.2214/ajr.11.6505

5. Wang C, Li C, Hsieh T, Chien S, Liu G, Tsai K (2004) Characterization of bone and soft-tissue tumors with in Vivo1H MR spectroscopy: initial results. Radiology 232:599-605. https://doi.org/10.1148/radiol.2322031441

6. Zhang J, Cheng K, Ding Y, Liang W, Ding Y, Vanel D et al (2013) Study of single voxel $1 \mathrm{H}$ MR spectroscopy of bone tumors: differentiation of benign from malignant tumors. Eur J Radiol 82:2124-2128. https://doi.org/10.1016/j. ejrad.2011.11.033

7. Qi Z, Li C, Li Z, Zhang K, Wang Q, Yu D (2009) Preliminary study of $3 T 1 \mathrm{H}$ MR spectroscopy in bone and soft tissue tumors. Chin Med J 122:39-43

8. Teixeira PAG, Ledrich M, Kauffmann F, Wamba J, Felblinger J, Blum A et al (2017) Qualitative 3-T proton MR spectroscopy for the characterization of musculoskeletal neoplasms: update on diagnostic performance and indications. AJR 208(6):1312-1319. https://doi.org/10.2214/AJR.16.17285

9. SahPL SR, Kandpal H, Seith A, Bandhu S (2008) In vivo proton spectroscopy of giant cell tumor of the bone. AJR 190:W133-W139

10. Fayad L, Salibi N, Wang X, Machado A, Jacobs M, Bluemke D et al (2010) Quantification of Muscle Choline Concentrations by Proton MR Spectroscopy at 3 T: Technical Feasibility. AJR 194:W73-W79. https://doi.org/ 10.2214/ajr.09.3125

11. Fayad LM, Wang X, Salibi N, BarkerPB JMA, Machado AJ (2010) A feasibility study of quantitative molecular characterization of musculoskeletal lesions by protonMR spectroscopy at 3T. AJR 195:W69-W75

12. Patni R, Boruah D, Sanyal S, Gogoi B, Patni M, Khandelia R, Gogoi N (2017) Characterisation of musculoskeletal tumors by multivoxel proton MR spectroscopy. Skelet Radiol 46:483-495. https://doi.org/10.1007/ s00256-017-2573-1

13. Fayad L, Bluemke D, McCarthy E, Weber K, Barker P, Jacobs M (2006) Musculoskeletal tumors: use of proton MR spectroscopic imaging for characterization. J Magn Reson Imag 23:23-28. https://doi.org/10.1002/ jmri.20448

14. Fayad L, Barker P, Jacobs M, Eng J, Weber K, Kuelsza P et al (2006) Characterization of musculoskeletal lesions on 3-T proton MR spectroscopy. AJR 188:1513-1520. https://doi.org/10.2214/AJR.06.0935

15. Lee C, Lee J, Kim D, Min H, Park B, Cho H et al (2010) Proton magnetic resonance spectroscopy of musculoskeletal lesions at $3 \mathrm{~T}$ with metabolite quantification. Clin Imaging 34(1):47-52. https://doi.org/10.1016/j.clinimag. 2009.03.013

16. Doganay S, Altinok T, Alkan A, Kahraman B, Karakas H (2011) The role of MRS in the differentiation of benign and malignant soft tissue and bone tumors. Eur J Radiol 79:e33-e37. https://doi.org/10.1016/j.ejrad.2010.12.089

\section{Publisher's Note}

Springer Nature remains neutral with regard to jurisdictional claims in published maps and institutional affiliations. 